FY 2005

\title{
FLOATING REFRIGERANT LOOP BASED ON R-134a REFRIGERANT COOLING OF HIGH-HEAT FLUX ELECTRONICS
}

Prepared by:

Oak Ridge National Laboratory

Mitch Olszewski, Program Manager

Submitted to:

Energy Efficiency and Renewable Energy

FreedomCAR and Vehicle Technologies

Vehicle Systems Team

Susan A. Rogers, Technology Development Manager

September 2005 
NATIONAL LABORATORY

MANAGED BY UT-BATTELLE

FOR THE DEPARTMENT OF ENERGY

\section{Floating Refrigerant Loop Based on R-134a Refrigerant Cooling of High-Heat Flux Electronics}

K. T. Lowe

Oak Ridge Institute for Science and Education

C. W. Ayers

J. S. Hsu

Oak Ridge National Laboratory

Publication Date: September 2005

Prepared by the

OAK RIDGE NATIONAL LABORATORY

Oak Ridge, Tennessee 37831

managed by

UT-BATTELLE, LLC

for the

U.S. DEPARTMENT OF ENERGY

Under contract DE-AC05-00OR22725 
This report was prepared as an account of work sponsored by an agency of the United States Government. Neither the United States Government nor any agency thereof, nor any of their employees, makes any warranty, express or implied, or assumes any legal liability or responsibility for the accuracy, completeness, or usefulness of any information, apparatus, product, or process disclosed, or represents that its use would not infringe privately owned rights. Reference herein to any specific commercial product, process, or service by trade name, trademark, manufacturer, or otherwise, does not necessarily constitute or imply its endorsement, recommendation, or favoring by the United States Government or any agency thereof. The views and opinions of authors expressed herein do not necessarily state or reflect those of the United States Government or any agency thereof. 


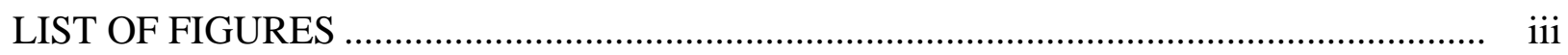

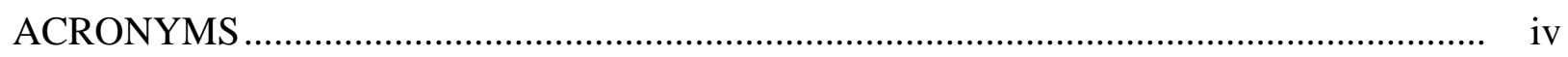

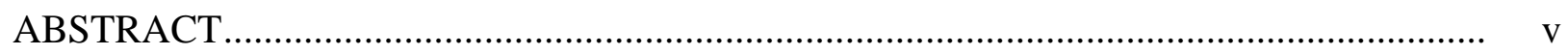

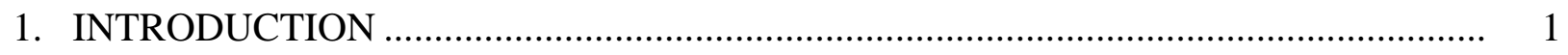

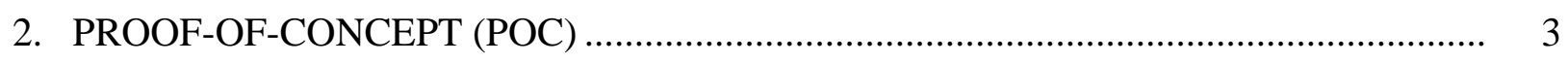

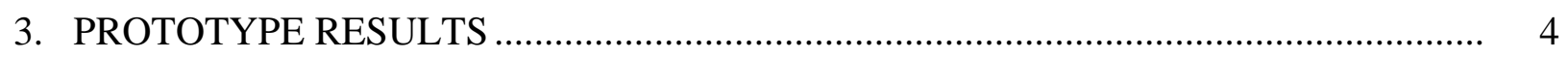

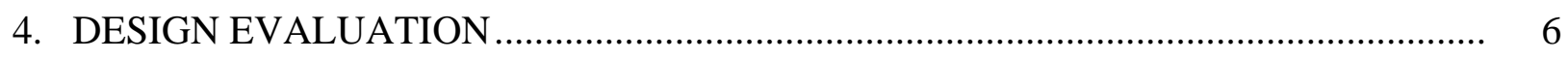

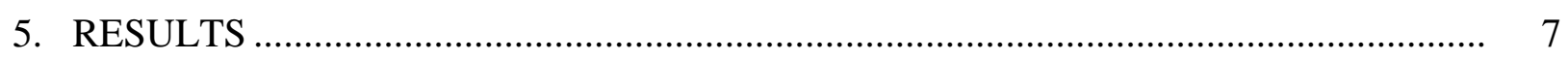

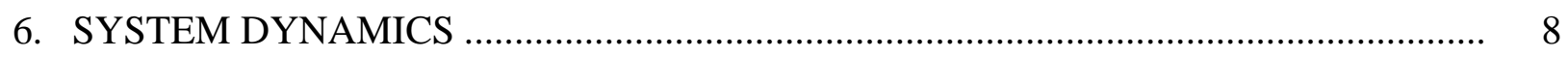

6.1 OPERATING CONDITIONS
$6.1 .1 \quad$ Steady Operation of the Floating Loop.......................................................... 8

6.1.2 Steady Operation of Loop and Automotive AC ............................................ 8

6.1.3 Transient Start-up of Automotive AC with Loop ........................................... 8

6.1.4 Transient Shut-down of Automotive AC with Loop ...................................... 9

6.2 CONTROL METHODS _.......................................................................................... 9

6.3 THERMODYNAMIC SYSTEM BEHAVIOR …………………………............... 9

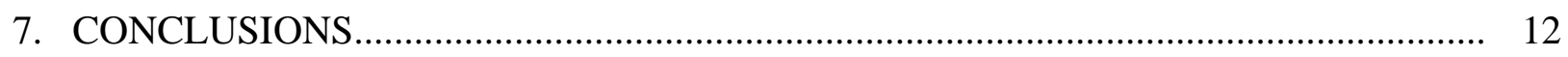

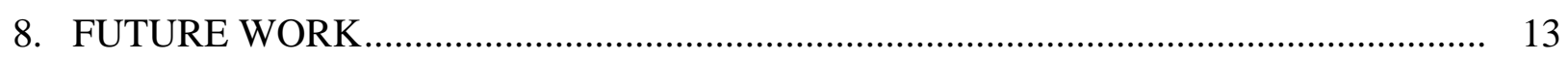

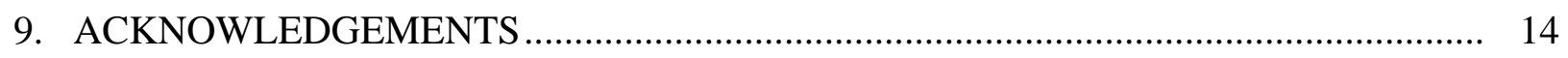

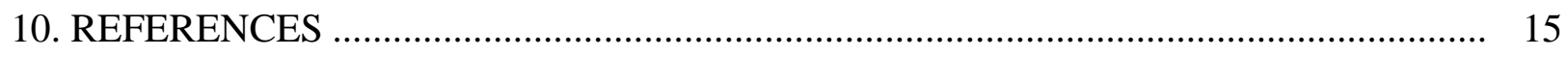

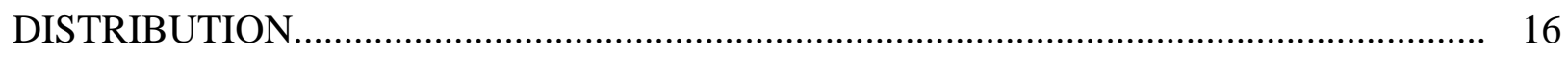




\section{LIST OF FIGURES}

Figure $\quad$ Page

$1 \quad$ Floating loop bench top apparatus with pump .................................................. 4

$2 \quad$ Schematic of floating loop adjoined to the cabinet AC system ............................... 5

$3 \quad$ Revised floating loop attached to full size sedan AC system in a cabinet................. 6

$4 \quad$ Floating loop/AC schematic with revisions........................................................... 7

$5 \quad$ P-h diagram of refrigeration cycles............................................................... 10

$6 \quad$ P-h diagram of floating-loop operations .................................................... 11 


\section{ACRONYMS}

AC

COP

DOE

FCVT

$\mathrm{HEV}$

ICE

IGBT

ORNL

PEEMRC

P-h

POC air conditioning coefficient of performance Department of Energy FreedomCAR and Vehicle Technologies hybrid electric vehicle internal combustion engine insulated gate bipolar transistor Oak Ridge National Laboratory Power Electronics and Electric Machinery Research Center Pressure-Enthalpy proof-of-concept 


\begin{abstract}
The Oak Ridge National Laboratory (ORNL) Power Electronics and Electric Machinery Research Center (PEEMRC) have been developing technologies to address the thermal issues associated with hybrid vehicles. Removal of the heat generated from electrical losses in traction motors and their associated power electronics is essential for the reliable operation of motors and power electronics. As part of a larger thermal control project, which includes shrinking inverter size and direct cooling of electronics, ORNL has developed U.S. Patent No. 6,772,603 B2, Methods and Apparatus for Thermal Management of Vehicle Systems and Components [1], and patent pending, Floating Loop System for Cooling Integrated Motors and Inverters Using Hot Liquid Refrigerant [2]. The floating-loop system provides a large coefficient of performance (COP) for hybrid-drive component cooling. This loop (based on R-134a) is integrated with a vehicle's existing air-conditioning (AC) condenser, which dissipates waste heat to the ambient air. Because the temperature requirements for cooling of power electronics and electric machines are not as low as that required for passenger compartment air, this adjoining loop can operate on the high-pressure side of the existing AC system. This arrangement also allows the floating loop to run without the need for the compressor and only needs a small pump to move the liquid refrigerant. For the design to be viable, the loop must not adversely affect the existing system. The loop should also provide a high COP, a flat-temperature profile, and low-pressure drop.

To date, the floating-loop test prototype has successfully removed $2 \mathrm{~kW}$ of heat load in a $9 \mathrm{~kW}$ automobile passenger AC system with and without the automotive AC system running. The COP for the tested floating-loop system ranges from 40-45, as compared to a typical AC system COP of about 2-4. The estimated required waste-heat load for future hybrid applications is $5.5 \mathrm{~kW}$ and the existing system could be easily scaleable for this larger load.
\end{abstract}




\section{INTRODUCTION}

The Oak Ridge National Laboratory (ORNL) Power Electronics and Electric Machinery Research Center (PEEMRC) has been developing technologies to address the thermal issues associated with hybrid vehicles. This work is part of an ongoing program called FreedomCAR and Vehicle Technologies (FCVT), performed for the Department of Energy (DOE). Removal of the heat generated from electrical losses in traction motors and their associated electronics is essential for the reliable operation of motors and power electronics. As part of a larger thermal control project, which includes shrinking inverter size and direct cooling of electronics, ORNL has developed U.S. Patent No. 6,772,603 B2, Methods and Apparatus for Thermal Management of Vehicle Systems and Components [1], and patent pending, Floating Loop System for Cooling Integrated Motors and Inverters Using Hot Liquid Refrigerant [2]. The floating-loop system provides a large coefficient of performance (COP) for hybrid-drive component cooling. COP is defined generally as

$$
\mathrm{COP}=\frac{\text { heat or cooling load }}{\text { input work }} \text {. }
$$

This loop (based on R-134a) is integrated with a vehicle's existing air conditioning (AC) condenser, which dissipates waste heat to the ambient air. Because the temperature requirements for power electronics and electric machines are not as low as that required for passenger compartment air, this adjoining loop can operate on the high-pressure side of the existing AC system. This arrangement also allows the floating loop to run without the compressor and only needs a small pump to move the liquid refrigerant. For the design to be viable, the loop must not adversely affect the existing system. The loop should also provide a high COP, a flattemperature profile, and low-pressure drop.

Currently hybrid electric vehicles (HEVs) use several different methods to cool the power electronics and hybrid-drive components. Other benchmarking work done at ORNL revealed current-cooling schemes by leading manufacturers which includes 50/50 ethylene-glycol/water heat sinks, forced and natural air convection, and oil circulation. While effective, the liquid sinks operate at a liquid temperature of $65^{\circ} \mathrm{C}$ [3] for vehicles using a separate radiator and 100$105^{\circ} \mathrm{C}$ when using the engine radiator. At junction temperatures of $125^{\circ} \mathrm{C}$, the silicon in power electronics devices begins to lose reliability and at $150^{\circ} \mathrm{C}$ the device begins to break down.

Furthermore, the windings in the motor(s) must be kept within the rating of the stator-insulation material. Without appropriate cooling, the motor performance will decrease; however, with improved cooling, the motor can run at a higher efficiency due to decreased resistance losses in the windings. Currently, there are several paths that are being considered for use in vehicles to remove heat from the various systems to the ambient air. These include the ethylene glycolwater internal combustion engine (ICE) cooling system $\left(105^{\circ} \mathrm{C}\right)$, a separate cooling loop with ethylene glycol and water at approximately $70^{\circ} \mathrm{C}$, transmission oil flowing through a separate cooler $\left(85^{\circ} \mathrm{C}\right.$ ), and the passenger compartment AC refrigerant system (currently R134a refrigerant at about $60^{\circ} \mathrm{C}$ ). 
The floating loop is a novel approach to the heat removal problem. It takes advantage of R-134a dielectric properties and temperature ranges, works well in compact heat exchangers, and could be used to cool larger structures like a motor housing. Previous work at ORNL demonstrated the very good dielectric nature of R-134a. Life tests with capacitors, an insulated gate bipolar transistor (IGBT), and a gate-driver printed circuit board showed no adverse affects when in direct contact with the refrigerant. The life tests have been conducted over a period of 15 months with periodic functional tests of the circuitry and visual inspections of the components and wiring occurring almost monthly [4].

With electronic components operating at higher efficiencies, fewer and smaller devices can be used. Ultimately, the development of the floating loop is the first step by ORNL in shrinking the size of the traction drive and its associated high heat-flux electronics while maintaining net power output [5]. 


\section{PROOF-OF-CONCEPT (POC)}

To demonstrate the refrigerant cooling concept for power electronics, three main project goals were set. The first step was to show that a significant heat load could be removed with no compressor, and the refrigerant could be moved through the system with a liquid pump or vapor blower, requiring minimal input power. This would prove that a low pressure drop, hightemperature, two-phase coolant loop would remove sufficient heat by itself.

The second step was to attach a similar loop to an automotive AC system where the loop and AC system would share the condenser. The objective of the second goal was to prove that the loop could share the condenser without adversely affecting the inventory behavior or performance of the automotive AC. In a full hybrid setup, the loop would operate constantly. The second configuration would realistically only come into question if the loop was used on an assist motor where the ICE runs all the time and the electric assist is more intermittent.

The last goal was to operate the floating loop and AC simultaneously. This test would be indicative of normal operation of the floating loop in a full hybrid configuration. The loop would be cooling a waste-heat load from the power electronic components while the AC system satisfied the passengers' compartment air temperature requirements. 


\section{PROTOTYPE RESULTS}

The first goal was met with a bench-top setup consisting of a variable speed pump, heat source, and condenser (Fig. 1). This cooling loop removed more than $2.1 \mathrm{~kW}$ of heat load with minimal input power. A vapor blower and pump were both tried with input power of $210 \mathrm{~W}$ and $48 \mathrm{~W}$, respectively. Both components managed similar loads, but the pump did so with less input power, as expected. The cooling loop resulted in a COP of 44 with this configuration.

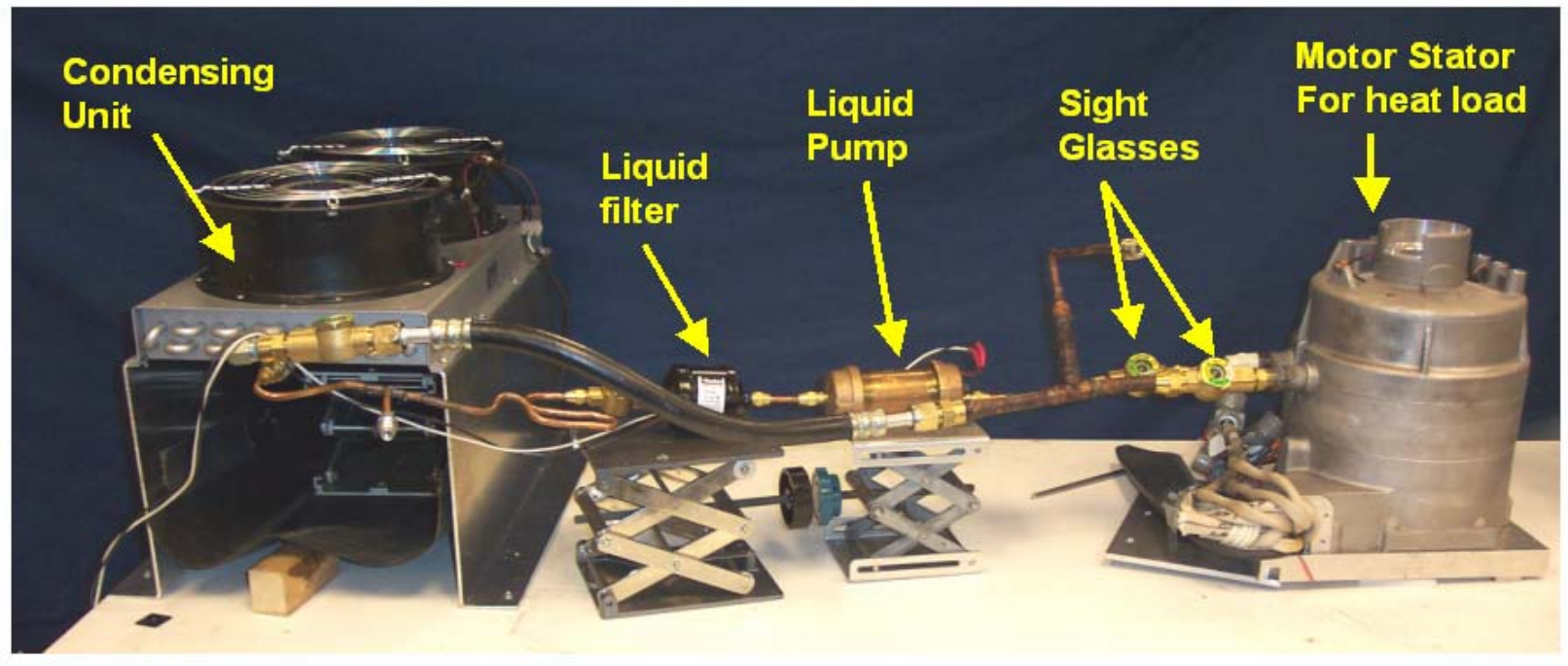

Fig. 1. Floating loop bench top apparatus with pump.

Another advantage of the pump was its compact size compared to the cumbersome fan housing. Limiting components on this bench-top setup included the size of the condenser and air flow across the condenser. Other broader issues that became apparent with this test were the flow passages through the motor housing and conduction-heat transfer from the motor windings to the refrigerant passages. These issues would need to be given consideration during motor-design stages when the R-134a loop-cooling method is being implemented.

For the second setup, a loop was attached to the high-pressure condenser section of a commercially available automotive AC system from a full-size sedan with a $9 \mathrm{~kW}$ capacity (Fig. 2). The loop-inlet line was placed at the lowest elevation possible to ensure the pump inlet would remain flooded with liquid without undue increases in system inventory. A $1 \mathrm{~kW}$ test load was initially used to prove loop operation. The loop maintained the test load near $30^{\circ} \mathrm{C}$. This specific system could also have handled a larger load, but these tests were not necessary for the proof of concept prototype.

After running, the loop was isolated from the stock AC system. The AC system produced adequate cooling after this test, which showed the loop had no adverse affect on AC system refrigerant-inventory behavior or refrigerant migration.

The final test involved operation of both systems simultaneously. The loop cooled the $1 \mathrm{~kW}$ test load and maintained it near $40^{\circ} \mathrm{C}$. This increase in temperature, as compared to the loop-only scenario, is a result of the increase in condenser-heat load when the compressor is running. 


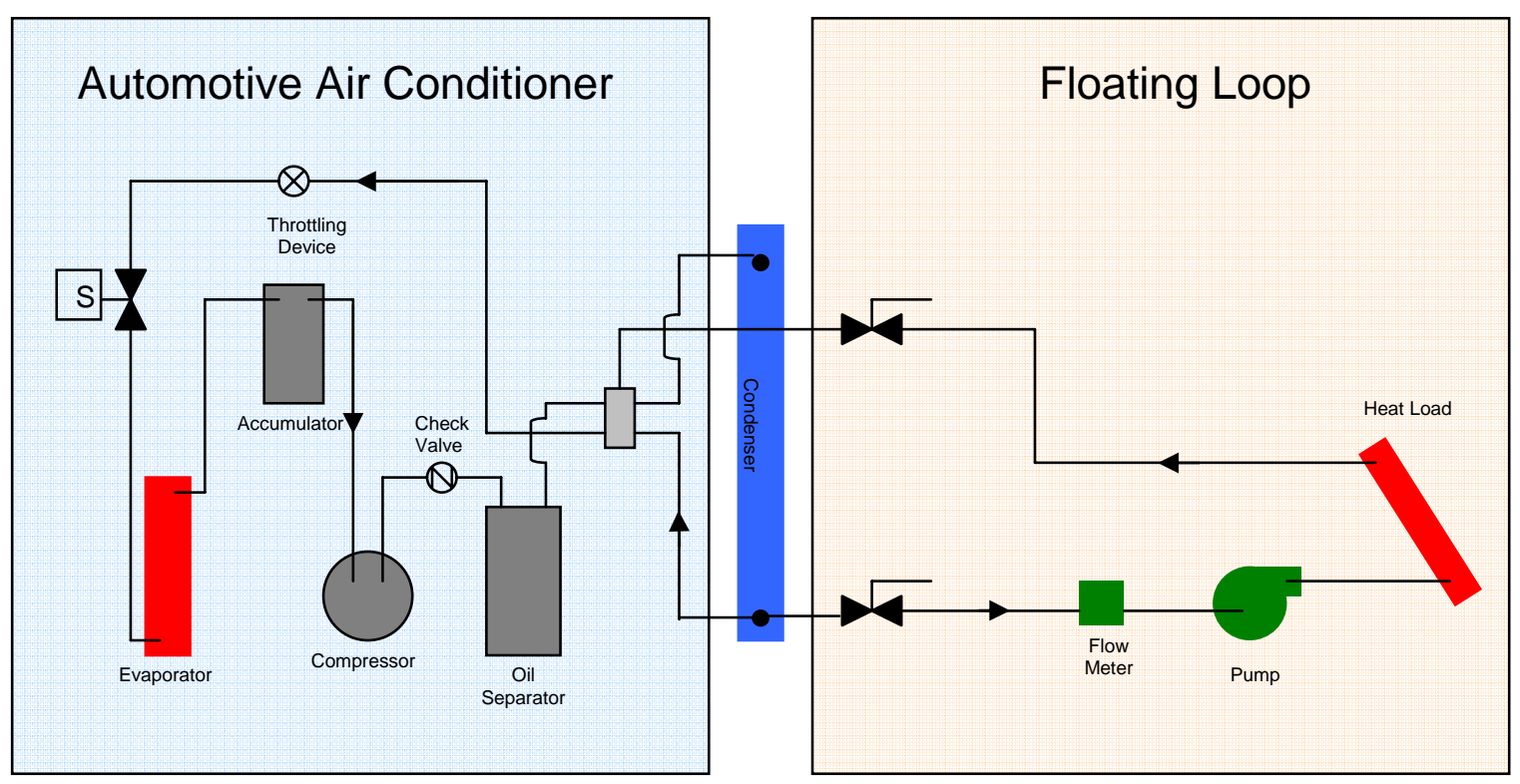

Fig. 2. Schematic of floating loop adjoined to the cabinet AC system.

When the loop runs by itself the condenser pressure is around 650-720 $\mathrm{kPa}$. When the AC system and loop are running simultaneously, the condenser pressure is $\sim 1 \mathrm{MPa}$. One key element in obtaining these stable results was to provide increased air flow across the condenser. For all tests, the condenser inlet air temperature was ambient laboratory temperature, $\sim 25^{\circ} \mathrm{C}$. 


\section{DESIGN EVALUATION}

Overall, the floating-loop system met the initial design goals; however, these tests revealed several issues with the loop/AC dynamics. Oil traps and liquid refrigerant traps had been unintentionally created during the integration of the loop into the automotive AC system. Liquid migration and flash boiling during the cycling of the compressor was also discovered to be a problem. Dry-out of the load is considered to be a major issue when designing for direct cooling of power electronics. If the liquid level drops significantly in the load or dry-out occurs, loss of two-phase cooling occurs and superheated vapor is produced which results in significantly reduced heat transfer and rapidly increasing junction temperatures.

In order to correct these problems, four major revisions were implemented:

1. Move check valve downstream of the oil separator in a horizontal position.

2. Move the solenoid valve closer to the condenser outlet.

3. Move the evaporator fan to blow out of the case instead of through the condenser. Add dedicated condenser fans (Fig. 3).

4. Move the pump position within the loop to upstream of the filter and flow meter.

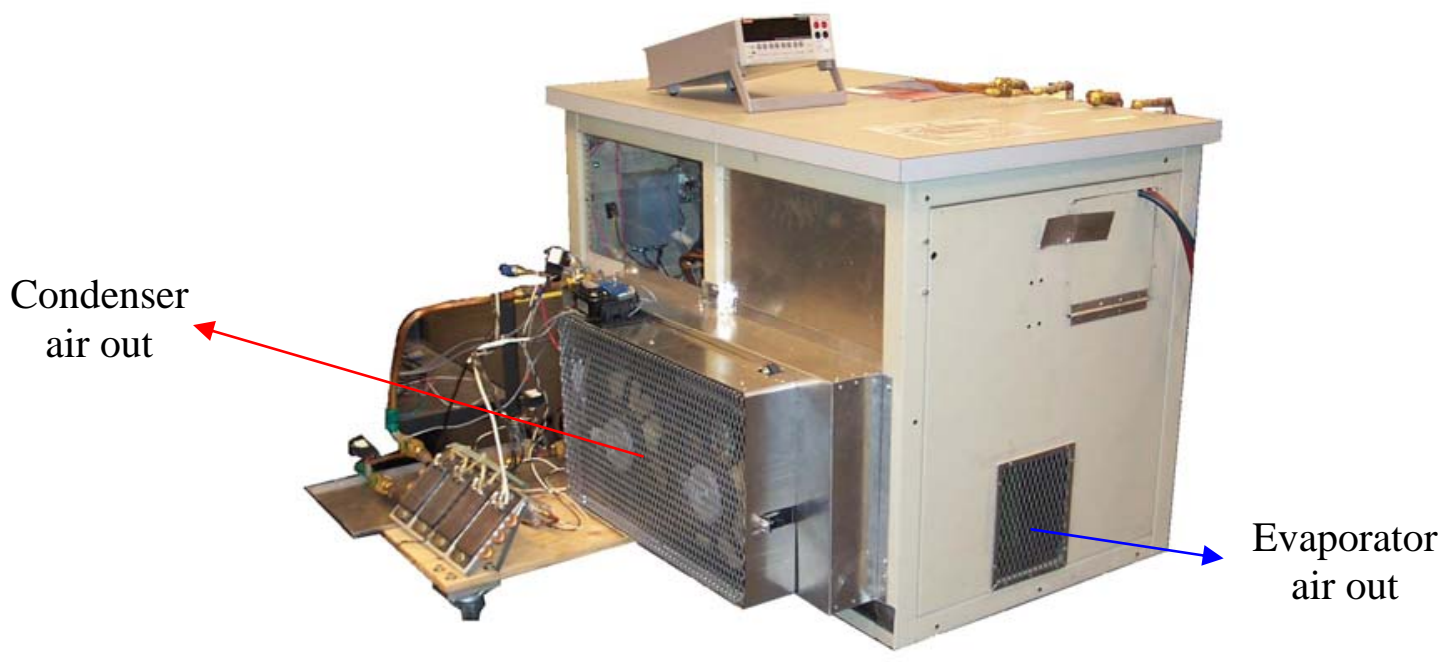

Fig. 3. Revised floating loop attached to full size sedan AC system in a cabinet.

During these changes, the original pump performance dropped due to unrelated pump motor electrical issues. One major design challenge had also been the electrical connections to the pump. A new pump was installed with commercially available high-pressure electrical terminals. 


\section{RESULTS}

After implementing these changes, the loop shown in Figs. 3 and 4 was retested at $1 \mathrm{~kW}$, $1.5 \mathrm{~kW}$, and $\sim 2 \mathrm{~kW}$. The $1 \mathrm{~kW}$ load had similar results as previous tests. Repeated tests of the cooling loop by itself resulted in maintaining the load temperature around $35^{\circ} \mathrm{C}$ with $\sim 1.5 \mathrm{~kW}$ of heat.

The AC unit was incorporated with the loop-test load at $1 \mathrm{~kW}$ and at $1.5 \mathrm{~kW}$, and the load was maintained at $37^{\circ} \mathrm{C}$ and $41^{\circ} \mathrm{C}$, respectively. This slightly higher temperature was expected because of the increase in operating pressure and, thus, higher saturation temperature. The flashboiling effects were minimal during these tests and no risk of load dry-out was obvious. The pump was at full power during these operations. When the $1.5 \mathrm{~kW}$ load was decoupled from the AC system, the floating-cooling loop returned to $34^{\circ} \mathrm{C}$.

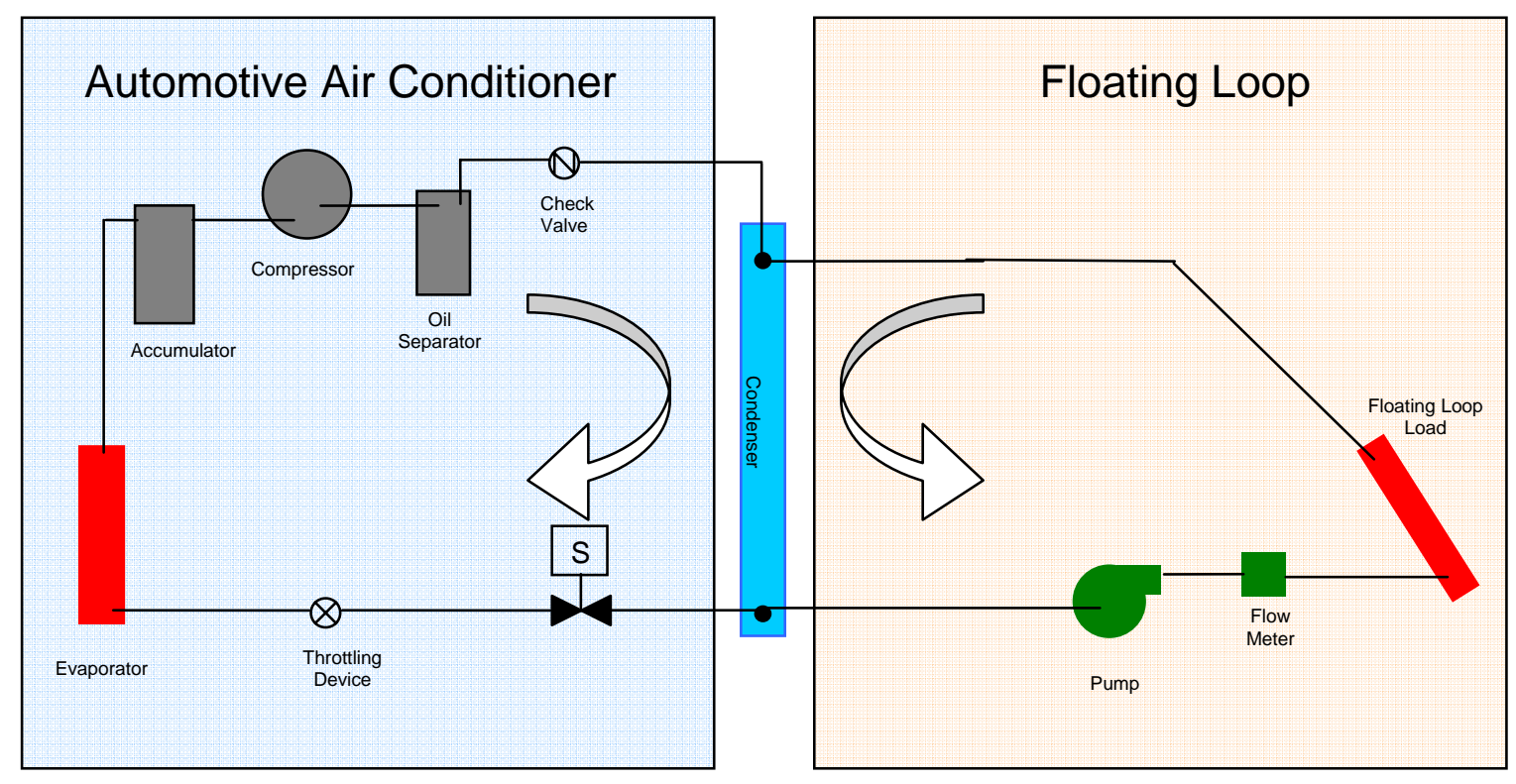

Fig. 4. Floating loop/AC schematic with revisions.

For test runs up to $1960 \mathrm{~W}$, the floating-cooling loop maintained the load near $38^{\circ} \mathrm{C}$. When the AC was coupled to the loop, the system continued to run well with the load surface temperature at $49^{\circ} \mathrm{C}$ with full pump power. When the AC was turned off, the flash-boiling effects appeared to be minimal. 


\section{SYSTEM DYNAMICS}

In order to assure a more robust design, the system instabilities previously mentioned in Section 4 were examined. When the pump was not at full power, several modes of system failure could arise: the pump would not supply enough liquid refrigerant to the loop in order to keep it wet, the differential pressure across the loop would collapse and cause backflow, or the cycling of the compressor would cause dry-out. During typical operation at $22^{\circ} \mathrm{C}$, four operating scenarios were encountered. These operating conditions are discussed individually to better understand the system behavior.

The four operating scenarios are: steady operation of floating loop, steady operation with automotive AC, transient start-up of automotive AC with loop, and the cycling off of the automotive air while maintaining loop operation. Each case presents unique operating requirements for which control methods are proposed and future design issues are discussed.

\subsection{OPERATING CONDITIONS}

\subsubsection{Steady Operation of the Floating Loop}

The first operating condition is for the continuous operation of the floating loop with no automotive AC. In this mode, the automotive AC system is isolated via a solenoid valve and check valve. It is crucial to locate the valves as close as possible to where the loop attaches to the system. Extra piping on the liquid side will increase the refrigerant inventory. The resistive load is maintained between $35-40^{\circ} \mathrm{C}$ with system pressures around $1 \mathrm{MPa}$. In this condition, the loop runs stable provided enough initial inventory is present in the loop.

\subsubsection{Steady Operation of Loop and Automotive AC}

The second operating condition occurs when the loop and automotive AC operate simultaneously in a steady state. When the compressor is engaged, the solenoid opens and both systems use the condenser. As long as loop inventory is maintained via the auxiliary pump, no problems arise. If the pump stalls, the risk for back flow and dry-out in the loop arises. With the additional loopheat loads of $2 \mathrm{~kW}$ from the floating loop, the passenger air temperature was near $50^{\circ} \mathrm{C}$.

During the operation of both systems, the possibility exists that liquid refrigerant could enter the suction side of the compressor; especially if the correct inventory balance between the loop and AC system is not maintained. This potentially catastrophic scenario has been addressed with loop controls to prevent liquid flood back.

\subsubsection{Transient Start-up of Automotive AC with Loop}

The third operating condition is the initial transient when the compressor is engaged. In this transient scenario, the compressor initiates the flow in the automotive AC path and the solenoid opens. The transient lasts for 30-40 seconds. During this transient, the automotive system is establishing the pressure differential between the condenser and evaporator. Because of the increase in saturation pressure of the condenser, the adjoining loop also increases in pressure 
which results in additional liquid in the loop. The temporary extra liquid inventory insures that the floating-loop load will not dry-out during this transient. The loop-liquid pump, however, needs to develop sufficient pressure to prevent loop backflow.

\subsubsection{Transient Shut-down of Automotive AC with Loop}

Although the onset of the compressor operation addressed above does not adversely affect the performance of the floating loop, the cycling off of the compressor causes the liquid inventory in the loop to decrease because of the condenser pressure decrease. This transient represents the last control scenario. Because the solenoid valve isolates the compressor, the balance of liquid and vapor inventory within the loop shifts and some flash boiling occurs.

The drop in pressure reduces the subcooling to the loop which induces flash boiling. The thermal inertia of the load maintains the flash boiling until its temperature is sufficiently reduced. If the loop-heat load and pump flow are appropriately scaled, then the loop-inventory level will decrease to the previous loop-operating levels. Otherwise, the potential risk for load dry-out rises.

\subsection{CONTROL METHODS}

Because of the potentially undesirable dry-out of this last operating scenario, several control solutions were proposed. The first was to operate the compressor with a variable-speed motor drive. The speed and thus the volumetric flow of the compressor could then be controlled. In practice, this method was not viable with the components in our cabinet system. This control method needs to be further investigated with different valving, an electric compressor, and a variable-speed drive.

The other control solution was to manually close the solenoid valve prior to compressor shutdown. This operation avoids dry-out conditions by overcharging the floating loop. With the solenoid closed, the compressor continues to feed inventory to the condenser and loop for a few seconds. This extra inventory at higher pressure is just enough to allow for the transient to occur without drying out the load. For the remaining tests with the floating-loop configuration, this control method was followed.

\subsection{THERMODYNAMIC SYSTEM BEHAVIOR}

In any system, it is desirable to understand the performance not only from an empirical view but also from the fundamental physics. In this case, that understanding can come from a thermodynamic study of the automotive AC system and floating loop. This analysis is meant to clarify the basic operation of the loop. Rough instrumentation and several simplifying assumptions, like constant-pressure condenser and evaporator, were made to produce this initial study.

Figure 5 depicts the measured behavior in the form of a Pressure-Enthalpy (P-h) diagram. Operating conditions shown are the AC system by itself (blue), and the combined floating loop and AC system (green and red). The separate heat flows out of the condenser and into the evaporator were obtained from air-side calculations and psychrometric measurements. 


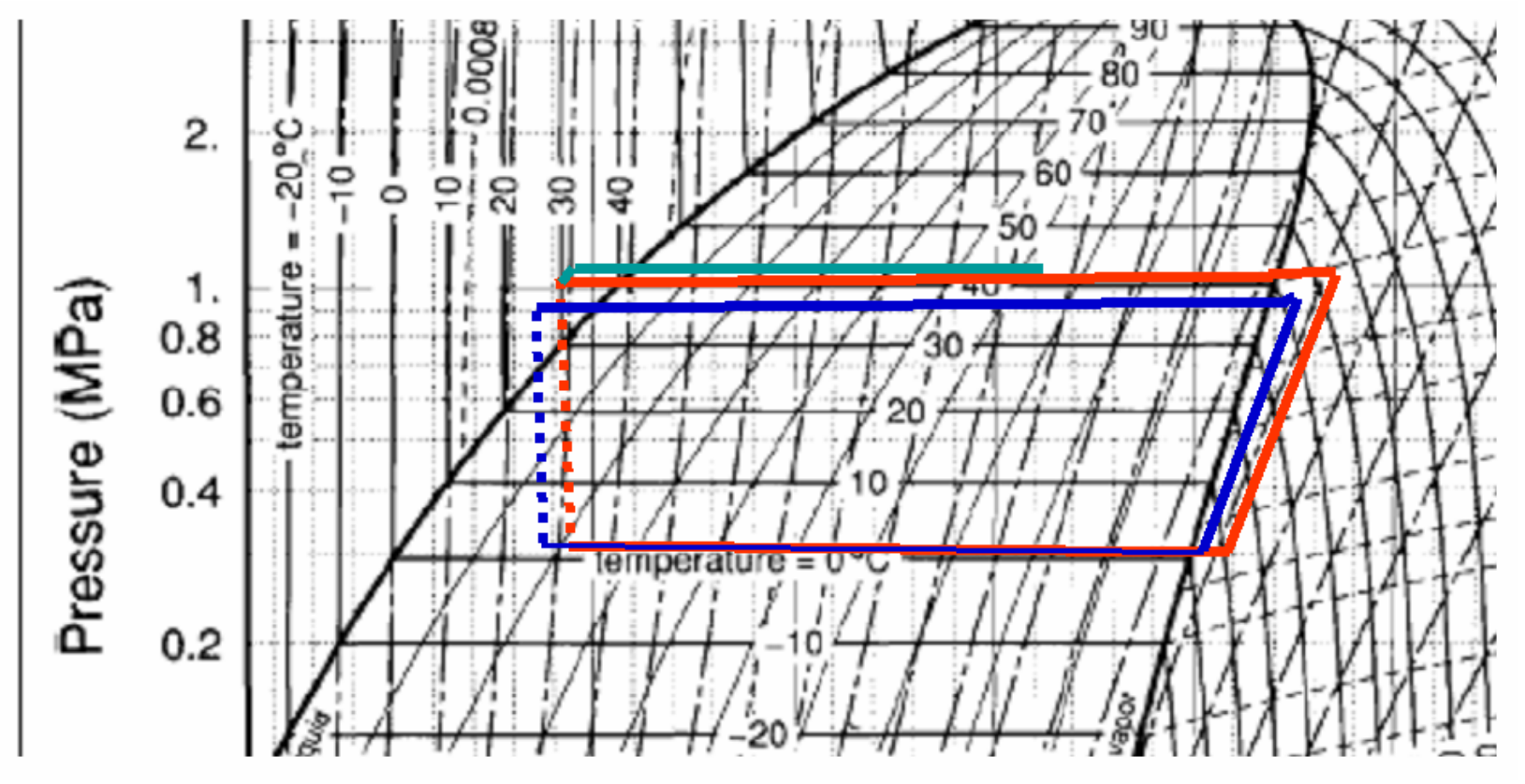

Fig. 5. P-h diagram of refrigeration cycles.

Condensate was also collected for confirmation by calculating the latent heat required to produce the measured amount of condensate. Various temperatures and pressures were used to locate compressor, condenser, evaporator, and floating-loop operating ranges. Detailed pressure drops and extensive calibrations were not performed for this analysis.

The baseline for the AC system (blue) is a normal refrigeration vapor-compression cycle. The cycle does show from the P-h diagram that the cabinet AC system was most likely low on inventory. Ideally, little or no superheat would be present at the exit of the evaporator and more subcooling, $10-15^{\circ} \mathrm{C}$, would be at the output of the condenser.

The combined system P-h diagram (red and green) also follows some of the same trends. The shift to the right indicates low inventory in the AC system. Ideally, the evaporator pressure would not change between the two operating scenarios, which the measurements confirmed. The addition of the loop increased the load on the condenser, which increased operating pressure with a constant air flow maintained. Calculations showed the baseline-condenser load (AC only) was $4.2 \mathrm{~kW}$ and the combined-condenser load (AC and loop) was $5.5 \mathrm{~kW}$. The floating loop additional load (pump and resistive load) was $1.1 \mathrm{~kW}$. These results indicate $5 \%$ error.

The green floating-loop path is missing some detail. Because of the physical setup, the loop should reenter near the condenser inlet. A mixing body, which receives superheated vapor from the compressor and a refrigerant quality from the loop, is not distinctly evident on this chart. More instrumentation is necessary to exactly determine the nature of this process.

Figure 6 shows the difference between operation of the floating loop as an isolated system and the floating loop working in conjunction with the automotive AC system. As mentioned 
previously, the incorporation of both systems results in an increase in condenser and loop pressure.

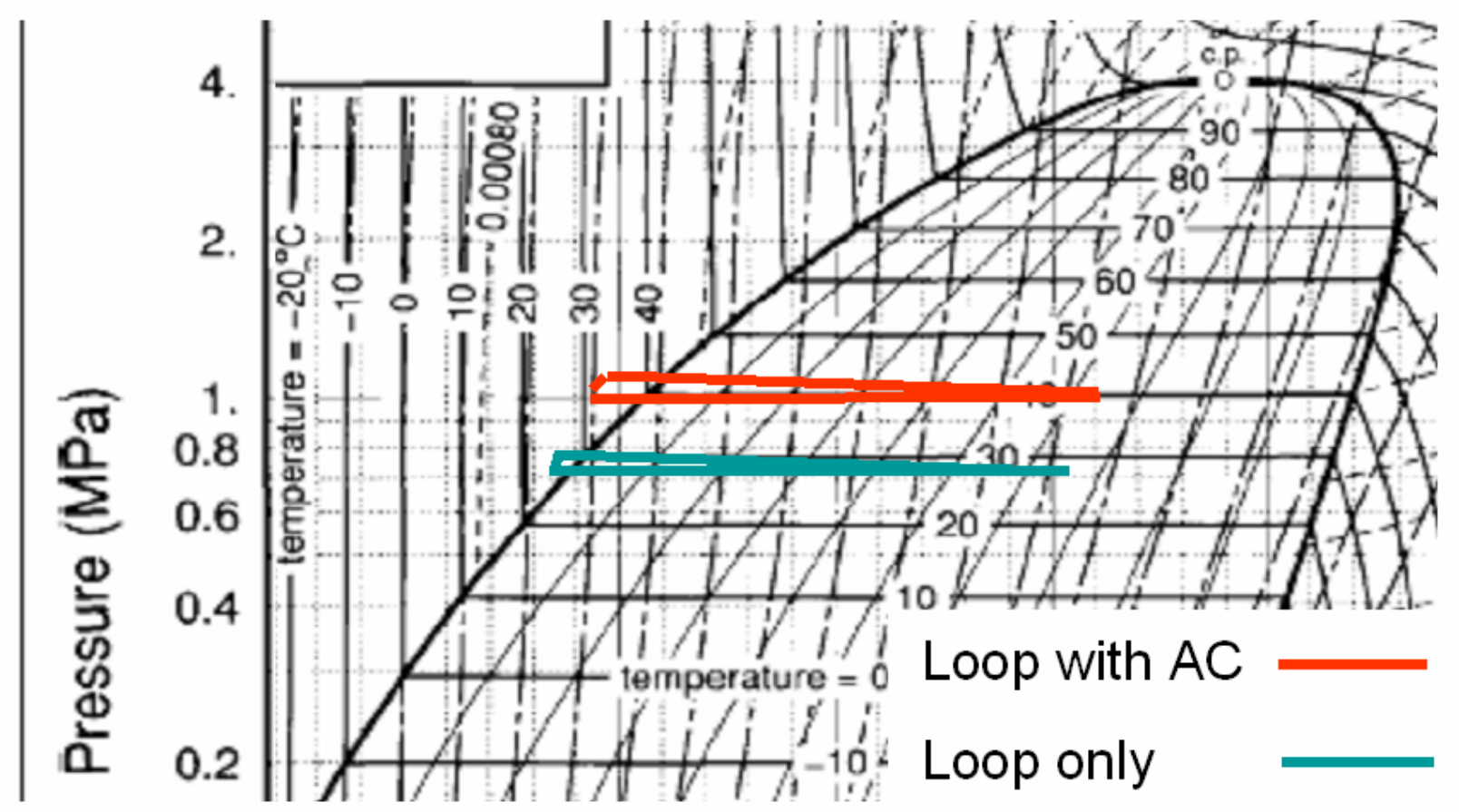

Fig. 6. P-h diagram of floating-loop operations.

The loop starts with subcooled liquid from the condenser. In these cases, the degree of subcooled liquid is subject to system charge. The red loop would have more subcooling with more adequate inventory. Increasing the total system inventory would increase the condenser inventory, which would increase the loop inventory. Thus, the isolated loop would start with more degrees of subcooling.

The resistive-heat load and the energy calculated from loop-liquid flow rates were comparable. This result is supported by the consistent enthalpy change seen between the two cases. 


\section{CONCLUSIONS}

A heat load placed in parallel with the existing evaporator/compressor arrangement can adequately cool several kilowatts of electronic heat load.

The floating loop can operate as an independent loop or in conjunction with the automotive AC system. The concept is not dependent on using R134a, but can use other refrigerants as well. In addition, this cooling concept can be utilized in an independent system, separate from the automotive AC system if an application requires this.

This cooling technique is suitable for full hybrid, hybrid assist, and fuel-cell vehicle configurations.

For operation as part of a $9 \mathrm{~kW}$ automobile cooling system, the ORNL floating-loop system has been proven to function well at $2 \mathrm{~kW}$, with a very attractive COP of $>40$.

System capacity is easily scalable for larger loads.

The operation of the floating-cooling loop results in four major running scenarios. Each one has the potential to run stably and reliably, subject to appropriate component sizing and controls.

A solenoid valve located close to the loop supply/condenser outlet to isolate the passenger AC components is crucial to the stable operation of the floating-cooling loop during AC compressor shutoff.

Methods of increasing liquid inventory in the condenser and floating loop are required to maintain a wet load during compressor transients. 


\section{FUTURE WORK}

Evaluate system operation utilizing a variable speed electric-hermetic compressor. An electric compressor allows an easier measurement of energy input to the system, and thus enables a better energy balance on the system.

A more accurate energy balance would be desired, resulting in a better understood and documented pressure-enthalpy envelope. The behavior of the loop discharge and compressor discharge mixing process needs to be better understood to ensure steady operation. A more comprehensive instrumentation system needs to be applied to get a total energy balance on the many system points. 


\section{ACKNOWLEDGEMENTS}

Special thanks to Dr. James Conklin for his input and recommendations relating to refrigeration loops and refrigerant properties.

Thanks to Chester Coomer, Marshall McFee, and Randy Wiles for all their help in construction, modifications, and testing support for the various floating-loop experiments. 


\section{REFERENCES}

1. J. S. Hsu et al., Total Thermal Management System for Hybrid and Full Electric Vehicles, U.S Patent 6,772,603, August 20, 2004.

2. J. S. Hsu et al., Floating Loop System for Cooling Integrated Motors and Inverters Using Hot Liquid Refrigerant, U.S. Patent Application 20050178148, Disclosure \#1300001378, filed August 25, 2004.

3. Toyota Motor Corporation, "Prius New Car Features 2004,” pp. TH-34 in NHW20 Series Pub. No. NCF255U, 2004.

4. J. B. Campbell, L. M. Tolbert, C. W. Ayers, and B. Ozpineci, “Two-Phase Cooling Method Using R134a Refrigerant to Cool Power Electronics Devices,” pp. 141-147 in Applied Power Electronics Conference (APEC 2005), March 6-10, 2005.

5. J. S. Hsu et al., Cascaded Die Mountings with Special-loaded Contact-bond Options, U.S. Patent 6,930,385, August 16, 2005. 


\section{DISTRIBUTION}

\section{Internal}

1. D. J. Adams

2. C. W. Ayers

3. J. Conklin

4. E. C. Fox

5. K. P. Gambrell

6. J. S. Hsu
7. K. T. Lowe

8. L. D. Marlino

9. M. Olszewski

10. M. Starke

11-12. Laboratory Records

\section{External}

13. T. Q. Duong, U.S. Department of Energy, EE-2G/Forrestal Building, 1000 Independence Avenue, S.W., Washington, D.C. 20585.

14. R. R. Fessler, BIZTEK Consulting, Inc., 820 Roslyn Place, Evanston, Illinois 60201-1724.

15. K. Fiegenschuh, Ford Motor Company, Scientific Research Laboratory, 2101 Village Road, MD-2247, Dearborn, Michigan 48121.

16. V. Garg, Ford Motor Company, 15050 Commerce Drive, North, Dearborn, Michigan 48120-1261.

17. E. Jih, Ford Motor Company, Scientific Research Laboratory, 2101 Village Road, MD1170, Rm. 2331, Dearborn, Michigan 48121.

18. A. Lee, Daimler Chrysler, CIMS 484-08-06, 800 Chrysler Drive, Auburn Hills, Michigan 48326-2757.

19. F. Liang, Ford Motor Company, Scientific Research Laboratory, 2101 Village Road, MD1170, Rm. 2331/SRL, Dearborn, Michigan 48121.

20. M. W. Lloyd, Energetics, Inc., 7164 Columbia Gateway Drive, Columbia, Maryland 21046.

21. Brenda Medellon, USCAR, brenda@uscar.org

22. M. Mehall, Ford Motor Company, Scientific Research Laboratory, 2101 Village Road, MD-2247, Rm. 3317, Dearborn, Michigan 48124-2053.

23. J. Rogers, Chemical and Environmental Sciences Laboratory, GM R\&D Center, 30500 Mound Road, Warren, Michigan 48090-9055.

24. S. A. Rogers, U.S. Department of Energy, EE-2G/Forrestal Building, 1000 Independence Avenue, S.W., Washington, D.C. 20585.

25. G. S. Smith, General Motors Advanced Technology Center, 3050 Lomita Boulevard, Torrance, California 90505.

26. E. J. Wall, U.S. Department of Energy, EE-2G/Forrestal Building, 1000 Independence Avenue, S.W., Washington, D.C. 20585.

27. B. Welchko, General Motors Advanced Technology Center, 3050 Lomita Boulevard, Torrance, California 90505.

28. P. G. Yoshida, U.S. Department of Energy, EE-2G/Forrestal Building, 1000 Independence Avenue, S.W., Washington, D.C. 20585. 